\title{
Paradigma Liberal dalam Pendidikan Global
}

\author{
Siswanto Masruri
}

There are at least three paradigms of education in the era of globalization: conservative, liberal, and critic. The paradigms mentioned could be attained through some processes implemented by the performers of global education. The liberal paradigm is of course brought about with the process of liberalization. Liberalism is therefore a paradigm and liberalization is a process. If the liberalization means as the application and cultivation of some strategic initiatives in the educational field, the writer believes that the majority of educational experts will agree with the purpose of the liberal paradigm. But, if it is intended as a free trade, and the cultural commodity of education is the same as the economic one, some of them will refuse it.In the field of education, there are still some centralistic and ceremonial practices, so that there wouldn't be any creativity. Consequently, the quality of Indonesian education is far from any other countries like Malaysia. In order to catch up the backwardness in education, the experts are expected to bring about the process of autonomy, decentralization, to consider culture of excellence and social welfare as the most important by developing 4 intelligences. Finally, the social prosperity could be obtained under the frame of global education.

Kata Kunci: liberalisasi, otonomi, desentralisasi dan pendidikan global

D ewasa ini, banyak terminologi ilmuilmu sosial dan agama yang berkembang pesat, tetapi membingungkan masyarakat. Substansi dan konteksnya kadang-kadang sama, tetapi ekspresi dan teksnya' berbeda. Dalam pendekatan ilmiah (keagamaan) misalnya istilah-istilah tekstual, skriptural, doktrinal, tradisional, naqliah, jabariah, dan normatif berada pada satu kelompok pendekatan; sedangkan istilahistilah dan pembaharuan, modernisasi, liberalisasi, kemerdekaan, kebebasan, dan pembebasan pada kategori yang lain. Sebagian besar istilah tersebut memiliki kesamaan arti, tetapi, oleh para pakar sering dibedakan dengan tujuan agar tidak sama dengan yang lain. Kedua istilah terakhir kemerdekaan dan kebebasan - sering dikaitkan dengan kondisi Indonesia pada tahun 1945 yang telah mencapai kemerdekaannya. Tetapi, paling tidak hingga akhir Orde Baru, bangsa ini - sekali pun telah merdeka - justru belum bebas dan mendapatkan kebebasannya.

' Tentang substansi dan ekspresi atau materi dan manifestasi, lihat antara lain, Isma'il Raji Al-Faruqi and Lois Lamya Al-Faruqi, The Cultural Atlas of Islam, diterjemahkan ke dalam bahasa Indonesia, Atlas Budaya Islam, Menjelajah Khazanah Peradaban Gemilang (Bandung: Mizan, 1998, 2003), 35-7. 
Topik: Globalisasi dan Liberalisasi dalam Bidang Pendidikan

Ketika periode Mekkah Muhammad SAW diangkat menjadi Rasul, ajaran utama yang disampaikan kepada umatnya adalah pembebasan dari budaya kemusyrikan menuju ketauhidan. La llaha Illa Allahadalah doktrin pembebasan dan liberalisasi yang sesungguhnya. Syahadat ini terdiri dari dua kata kunci: nafyun atau negasi (la ilaha) dan itsbat atau konfirmasi (illa Allah). Ajaran ini sesungguhnya memiliki arti pembebasan yang sebenarnya. Metode empiris dan induktif yang menurut sebagian pengamat dirintis oleh Roger Bacon (1214-1294 M) dan Francis Bacon (1561-1627 M) yang kemudian menjadi cikal bakal kemajuan Barat Abad XVII bahkan merupakan kongkretisasi dari semangat Tauhid dalam Islam tersebut. ${ }^{2}$

Kalau sekarang banyak pengamat yang mengintrodusir istilah liberalisasi dalam konteks pendidikan, maka muncul banyak pertanyaan. Apakah yang dimaksud dengan liberalisasi itu hanya dikaitkan dengan wacana 'pasar bebas' sehingga pendidikan harus disetarakan dengan komoditi perdagangan dan ekonomi? Atau, apakah liberalisasi itu hanya dapat dimaknai dengan pembebasan dari penindasan para kapitalis pendidikan $?^{3}$ Atau, liberalisasi itu dimaksudkan sebagai pembaharuan sehingga praktek-praktek pendidikan yang sudah out of date harus diganti dengan yang baru? Atau, liberalisasi itu mengandung pengertian desentralisasi atau otonomi pendidikan sehingga praktek-praktek pendidikan tidak harus mengacu pada satu model atau pola tertentu? Atau, apakah liberalisasi itu sudah merupakan mindset umat yang sejak dahulu telah membebaskan diri mereka dari budaya kemusyrikan menuju ketauhidan sehingga empirisme lebih mudah dilakukan? Untuk membahas dan menjawab semuanya itu, khususnya yang terkait dengan liberalisasi dan liberalisasi pendidikan, artikel ini akan mengkritisi sebuah proses liberalisasidalam pengertian yang luas dan sedikit berbeda.

\section{Liberalisasi: Forum WTO dan GATTS}

Mark Olssen, John Codd dan AnneMarie O'Neill pernah menyatakan bahwa,

"Education policy in the twenty-first century is the key to global security, sustainability, and survival. The era of globalization brings urgency to the need for a new world order in which nation-states can develop policies that will contribute to and sustain forms of intemational govemance. We argue that education policies are central to such a global mision".

2 Roger Bacon dan Franscis Bacon sebenarrnya hanya merupakan kurir-kurir ilmu pengetahuan dari Dunia Barat ke Dunia Islam, bukan perintis dan penemu metode empiris atau induktif sebagaimana diakui oleh sebagian pengamat Barat. Lihat, S.I. Poeradisastra, Sumbangan Islam kepada IImu dan Peradaban Modem (Jakarta: P3M, 1981, 1986), vil; Lihat, J.W. Drapper, History of the Conflict Between Religion and Science (London: 1966) dan Robert Brifault, The Making of Humanity (London: 1919), 202; Lihat juga, Muhammad Iqbal, The Reconstruction of Religious Thought in Islam dan Ali Sami al-Nashar, Manahij al-Bahts 'Inda Mufakkir al-Islam wa Naqd al-Muslimin if alManthiq al-Aristhatalisi (iskandariyah: Dar al-Fikr al-'Arabi, 1947), 25.

3 FrancisWahono, Kapitalisme Pendidikan, Antara Kompetisi dan Keadilan (Yogyakarta: Insist Press, Cindelaras Bekerjasama dengan Pustaka Pelajar, 2001), 105.

${ }^{4}$ Mark Olssen, John Codd and Anne-Marie O'Neill, Education Policy: Globalization, Citizenship and Democracy (London: Sage Publications, 2004), 1. 
Pernyataan ketiga ahli pendidikan dari New Zealand di atas menegaskan bahwa kebijakan bidang pendidikan pada abad ini merupakan kunci dari keamanan, keberianjutan, dan kehidupan global. Pada era globalisasi di mana jarak antara negara yang satu dengan yang lainnya semakin dekat, maka kebijakan apa pun (termasuk misalnya liberalisasi, desentralisasi dan deseremonialisasi pendidikan) akan menjadi sangat sentral. Karena itu, persaingan global bidang pendidikan tidak dapat dihindari dan akan dapat diantisipasi.

Dalam dunia yang semakin sempit dan padat, yang ditandai oieh semakin mudah diterobosnya batas-batas nasional oleh kekuatan destruktif yang mengerikan, meluasnya kemampuan teknologi dan komunikasi yang begitu pesat, umat manusia hidup dalam intimitas yang mendekati sempurna. Banyak peristiwa hukum, sosial, politik, ekonomi, dan budaya yang terjadi di bagian dunia yang satu, dapat segera diketahui oleh bagian dunia yang lain. Tetapi, kemampuan untuk saling mempengaruhi kehidupan satu sama lain ke arah yang lebih baik atau lebih buruk belum pernah mencapai lingkup dan kondisi sebagaimana saat ini.

Pada akhir Desember 2005, Hongkong mendadak kebanjiran belasan ribu pendatang dari berbagai negara. Magnet yang menarik para pejabat perdagangan dari 149 negara, kelompok aktivis, dan tentu pencari berita ke bekas koloni inggris itu apalagi kalau bukan Konperensi Tingkat Menteri Organisasi Perdagangan Dunia (WTO). Menurut Pascal Lamy, Direktur Jenderal WTO, konperensi ini harus mampu menuju penyelesaian Putaran Doha. Pernyataan ini menyiratkan kekhawatiran tidak tuntasnya Putaran Doha yang ditargetkan usai dalam dua tahun. ${ }^{5}$
Sejak edisi Doha, tawar-menawar dalam sidang WTO memang lebih ketat. Doha merupakan seri pertama ketika negara maju berjanji membuka telinga lebih lebar terhadap kepentingan mitra mereka yang perekonomiannya masih berkembang. Kebijakan ini merupakan buntut dari panasnya perdebatan antara kelompok negara maju dengan negara berkembang dalam pertemuan di Seattle, Amerika Serikat. Kelompok negara berkembang ketika itu memberi label kepada WTO sebagai klub negara kaya. Tidak hanya itu, kelompok negara berkembang juga mengancam memboikot tiap ageñda perundingan WTO apabila kepentingan mereka tidak diacuhkan.

Pertarungan kepentingan di WTO tidak hanya berlangsug antara kelompok negara maju dan negara berkembang. Kelompok negara sejahtera (maju) pun terpecah ke dalam dua kubu. Yang pertama adalah kelompok lobi perusahaan multinasional di sektor manufaktur dan jasa. Mereka inilah yang mengusung tinggi-tinggi obor perdagangan bebas. Untuk negara maju seperti Amerika Serikat, kelompok ini penting karena menyumbang produk domestik bruto terbesar. Di Amerika Serikat, sektor industri menyumbang hampir 20 persen. Kontribusi terbesar masih dipegang sektor jasa yaitu 79 persen. Kedua, kedudukan para petani berada pada sisi yang lain. Kubu ini yang paling anti agenda WTO. Bagi petani negara maju sekalipun, pemangkasan proteksi merupakan lonceng kematian.

Di Uni Eropa, kontribusi sektor pertanian terhadap produk domestik bruto tidak pernah di atas 10 persen. Pekan silam, delegasi Uni Eropa dan Amerika bahkan

s Tempo, Edisi 19-25 Desember 2005, 20-21. 
sempat bersitegang. Amerika bersikeras meminta Uni Eropa memotong tarif impor produk pertanian. Sebaliknya, Uni Eropa menuduh pemerintah Amerika memanjakan petaninya melalui paket bantuan pangan ke negara-negara miskin. Lalu di mana posisi Indonesia? Dalam pertemuan dengan masyarakat Indonesia di Hong Kong, Menteri Perdagangan Mari Elka Pangestu menyatakan,

"Indonesia tidak akan membiarkan industri pertanian dalam negeri bertarung bebas. Jalan yang akan ditempuh adalah mengegolkan kriteria special product dan merumuskan special safeguardmechanism untuk produk pertanian seperti beras. Tiga kriteria special product yang diusulkan Indonesia adalah produk yang terkait dengan ketahanan pangan, kemiskinan, dan pembangunan daerah: Selain mengusulkan kriteria, Indonesia juga masih harus menegosiasikan periode pemberlakuan status special product itu dan besaran tarifnya." ${ }^{\text {"6- }}$

WTO yang bersidang sampai hari Minggu Desember 2005 juga membicarakan rencana liberalisasi pendidikan. Sebagaimana diketahui, klasifikasi penyediaan jasa bidang pendidikan tinggi dalam lingkup General Agreement on Trade, Tarrifs, and Services (GATTS) di WTO meliputi: (1) cross border supply. jarak jauh, internet, on line, degree program; (2) consumption abroadt. belajar di luar negeri; (3) commercial presence: partnership, subsidiary, twinning arrangement dengan perguruan tinggi lokal; (4) presence of natural: tenaga-tenaga pengajar asing di perguruan tinggi lokal. Penandatanganan perjanjian dan klasifikasi penyediaan jasa (pendidikan) memiliki konsekuensi bahwa mulai tahun 2006, berbagai lembaga pendidikan asing akan diperbolehkan masuk ke negara-negara berkembang termasuk Indonesia. Perjanjian itu meliputi 4 (empat) sektor jasa: (1) profesional; (2) energi; (3) kesehatan; dan (4) pendidikan.?

Merespon isu liberalisasi pendidikan, para pakar berbeda pendapat dalam menanggapi rencana tersebut. Forum Rektor misalnya secara tegas menolak rencana liberalisasi. Ketua Forum, Wibisono Hardjopranoto, mengatakan bahwa liberalisasi akan menyebabkan pendidikan menjadi komoditas perdagangan dan ekonomi. Padahal, pendidikan mestinya menjadi kegiatan budaya untuk mencerdaskan bangsa. Namun, Rektor Universiatas Negeri Surabaya ini tidak keberatan bila lembaga pendidikan asing yang masuk ke Indonesia adalah pendidikan yang bersifat teknis seperti kursus komputer.

Rektor UGM Sofian Effendi memiliki pendapat yang-sama ketika menyatakan bahwa Indonesia belum saatnya menghadapi liberalisasi pendidikan. Mendiknas Bambang Sudibyo juga berpendapat sama. Menurut dia, tidak ada konsep liberalisasi dalam pendidikan. Sebaliknya, Menko Kesra Aburizal Bakrie berseberangan sikap. Menurut dia, Indonesia harus belajar dari kemunduran pendidikan di Inggris yang tidak melakukan reformasi. Dia percaya, dengan liberalisasi dan kompetisi yang kuat, kualitas pendidikan dapat meningkat.

Dengan semangat globalisasi dan liberalisasi seperti yang diinginkan GATTS, Indonesia, baik menerima maupun menolak perjanjian tersebut, pasti akan terpengaruh meski tidak harus dirugikan. Institusi pendidikan asing yang nantinya boleh masuk ke Indonesia hanyalah perguruan tinggi yang mau bermitra dengan lembagalembaga pendidikan lokal. Oleh karena itu, lembaga-lembaga pendidikan Indonesia
${ }^{6} \mathrm{lbid}$.
${ }^{7}$ SKH Jawa Pos, Kamis, 5 Mei 2005, 7. 
mulai sekarang harus bekerja lebih keras dengan melakukan reorientasi pendidikan, reformasi epistemologi keilmuan dan kelembagaan, dekonstruksi dan rekonstruksi kurikulum (knowledge based on economy, HAM, multikulturalisme, demokratisasi, dan lain sebagainya), serta peningkatan kualitas manajemen. Terkait dengan perkembangan global tersebut, lembaga-lembaga pendidikan Indonesia diharapkan mampu melakukan antisipasi dan memberikan solusi secara akademis sesuai kebutuhan masyarakat, permasalahan, dan tantangan global masa depan.

Hampir semua negara yang pernah dijajah seperti Indonesia memang mengalami keterpurukan dalam bidang sosial politik, ekonomi, dan pendidikan. Setelah terbebas dari penjajahan dan memperoleh kemerdekaan pada tahun 1945, Pemerintah Indonesia mencoba memahami sebabsebab keterpurukan tersebut, melakukan renungan dan evaluasi serta berusaha mencari jalan keluarnya. Secara intelektual, para founding fathers dan pelaku pendidikan telah mencurahkan tenaga dan pikiran mereka untuk mengatasi berbagai masalah, khususnya bidang pendidikan. Secara kelembagaan, mula-mula mereka mendirikan pesantren sebagai lembaga pendidikan yang indigenous Islam Indonesia dan lembaga pendidikan model sekolah (Barat). Tidak puas dengan kedua lembaga tersebut, mereka mendirikan lembaga pendidikan model madrasah.

Kebingungan dan dilema kelembagaan akademik para pelaku pendidikan dan masyarakat Indonesia tersebut akhirnya menimbulkan dikotomi ilmu antara umum (baca: iptek) dan agama yang hingga kini belum dapat diatasi. Negara ini sebenarnya juga telah memiliki sekian banyak pemikir, uléma, kiai, dan ahli bergelar Sarjana, Ma- gister, Doktor, Guru Besar dalam berbagai bidang (sosial politik, ekonomi, dan pendidikan). Kekayaan intelektual Indonesia seperti itu seharusnya mampu merespon berbagai keterpurukan dan memberikan solusi alternatif terhadap persoalanpersoalan pendidikan dan kemanusiaan universal yang hingga saat ini masih dirasakan bersama.

Persoalan-persoalan tersebut antara lain kebodohan massal, kemiskinan struktural, ekonomi kapitalis, korupsi 'sosialis' (kolektif), terorisme, konflik intra dan antarnegara, serta musibah alamiah yang menimpa sebagian bangsa Indonesia. Disebabkan oleh berbagai dilema dan minimnya 'dana', para ahli ternyata belum mampu (Jawa: mitayani) memberikan solusi secara tuntas dan menyeluruh sehingga menimbulkan pertanyaan: "Mengapa kualitas pendidikan Indonesia masih rendah, belum kompetitif, dan kurang diperhitungkan secara' internasional?" Mengapa kesenjangan pendidikan masih terjadi di mana-mana dan dalam berbagai dimensinya? Apanya yang salah? Sistem pendidikan nasional, sumber dana, atau sumber daya manusianya? Lebih dari itu, untuk meningkatkan kualitas pendidikan bangsa secara menyeluruh dan evolusioner, para pelaku pendidikan negeri ini harus memulainya dari mana? Dari input, proses, manajemen, epistemologi keilmuan, atau dengan melakukan proses liberalisasi, desentralisasi, deseremonialisasi pendidikan guna mencapai budaya unggul dan sejahtera bagi para pelakunya secara keseluruhan? Jawaban pasti tentu harus melalui kajian intensif terlebih dahulu, eksperimen, penelitian terencana, gradual, dan komprehensif. 


\section{Paradigma Liberal dalam Pendidikan}

Para praktisi pendidikan (guru, dosen, pelatih, pemandu) di berbagai lembaga pendidikan, atau pendidikan rakyat (popular education) di kalangan buruh, petani dan rakyat miskin, banyak yang tidak sadar bahwa mereka tengah terlibat dalam suatu pergumulan politik dan ideologi melalui arena pendidikan. Mereka memahami bahwa pendidikan merupakan suatu kegiatan mulia yang mengandung kebajikan dan berwatak netral. Dunia pendidikan kemudian dikejutkan oleh asumsi bahwa setiap usaha pendidikan yang selalu dimuliakan dan diasumsikan mengandung kebajikan tersebut mendapat kritik mendasar oleh almarhum Paulo Freire pada awal tahun 70 an dan Ivan Illich pada dekade yang sama. ${ }^{8}$

Freire dan llich menyadarkan banyak orang bahwa pendidikan yang selama ini hämpir dianggap sakral dan penuh kebajikan ternyata juga mengandung penindasan. Namun demikian, berbagai kritik mendasar tersebut justru semakin mendewasakan dunia pendidikan karena memperkaya berbagai upaya pencarian model pendidikan sehingga melahirkan pengalaman lapangan di berbagai belahan dunia mengenai praktek pendidikan sebagai bagian dari aksi kultural dan transformasi sosial. ${ }^{9}$

Dewasa ini, untuk kesekian kalinya, pendidikan tengah diuji untuk mampu memberikan jawaban yang sulit yakni antara melegitimasi atau melanggengkan sistem dan struktur sosial yang ada, atau pendidikan harus berperan kritis dalam melakukan perubahan sosial dan transformasi menuju dunia yang lebih adil. Kedua peran dilematis pendidikan tersebut hanya dapat dijawab melalui pemilihan paradigma pendidikan yang mendasarinya. Untuk memahami paradigma tersebut akan sedikit diulas mengenai berbagai paradigma pendidikan dan implikasinya yakni konservatif, liberal, dan kritis. ${ }^{10}$

Pertama, Paradigma Konservatif. Bagi mereka, ketidaksederajatan masyarakat merupakan suatu hukum keharusan alami, suatu hal yang mustahil dapat dihindari serta merupakan ketentuan sejarah atau bahkan takdir Tuhan. Perubahan sosial bagi mereka bukanlah sesuatu yang harus diperjuangkan karena perubahan hanya akan membuat manusia lebih sengsara. Dalam bentuknya yang klasik, paradigma konservatif dibangun berdasarkan keyakinan bahwa masyarakat pada dasarnya tidak dapat merencanakan perubahan atau mempengaruhi perubahan sosial. Hanya Tuhan lah yang merencanakan keadaan masyarakat dan hanya Dia yang tahu makna di balik semuanya itu. Dengan pandangan seperti ini, kaum konservatif tidak menganggap rakyat memiliki kekuatan atau kekuasaan untuk merubah kondisi mereka."

Dalam perjalanan selanjutnya, paradigma konservatif cenderung menyalahkan subyeknya. Bagi kaum konservatif, mereka yang menderita yakni orang-orang miskin, buta huruf, kaum tertindas dan mereka yang di penjara, menjadi demikian karena salah mereka sendiri. Banyak orang lain yang

8 Mansour Fakih, "Ideologi dalam Pendidikan" dalam William F. O'Neill, Educational Ideologies: Contemporary Expression of Educational Philosophies, diterjemahkan ke dalam bahasa Indonesia, Ideologi-ideologi Pendidikan (Yogyakarta: Pustaka Pelajar, 2001), $x$.

$s$ Ibid.

10 Paulo Freire dkk. menyebutkan 4. paradigma yakni fundamentalis, konservatif, liberal, dan anarkis. Lihat, Paulo Freire, Ivan Illich, Erich Fromm dkk., Menggugat Pendidikan (Yogyakarta: Pustaka Pelajar, 1999, 2001), vii-xxxix.

11 Ibid. 
ternyata dapat bekerja keras dan berhasil meraih sesuatu. Banyak orang ke sekolah dan belajar untuk berperilaku baik dan oleh karenanya tidak di penjara. Kaum miskin haruslah sabar dan belajar untuk menunggu sampai giliran mereka datang. Karena, pada akhirnya, semua orang kelak akan mencapai kebebasan dan kebahagiaan. Oleh karena itu, kaum konservatif melihat pentingnya harmoni dalam masyarakat dan menghindarkan konflik dan kontradiksi.

Kedua, Paradigma Liberal. Golongan ini berangkat dari keyakinan bahwa memang ada masalah di masyarakat, tetapi bagi. mereka, pendidikan tidak ada kaitannya dengan persoalan politik dan ekonomi masyarakat. Dengan keyakinan seperti itu, tugas pendidikan juga tidak ada sangkutpautnya dengan persoalan politik dan ekonomi. Sungguhpun demikian, kaum liberal selalu berusaha untuk menyesuaikan pendidikan dengan keadaan ekonomi dan politik di luar dunia pendidikan dengan jalan memecahkan berbagai masalah pendidikan dengan usaha reformasi 'kosmetik'. Umumnya, yang dilakukan adalah perlunya membangun kelas dan fasilitas baru, memoderenkan peralatan sekolah dengan pengadaan komputer dan laboratorium yang lebih canggih, serta berbagai usaha untuk menyehatkan rasio murid-guru. Selain itu, juga berbagai investasi untuk meningkatkan metodologi pengajaran dan pelatihan yang lebih efisien dan partisipatif seperti kelompok dinamik (group of dynamics) dan sebagainya. ${ }^{12}$

Akar dari pendidikan di atas adalah Liberalisme yakni suatu pandangan yang menekankan pengembangan kemampuan, melindungi hak, dan kebebasan, serta mengidentifikasi problem dan upaya perubahan sosial secara instrumental demi menjaga stabilitas jangka panjang. Konsep pendidikan dalam tradisi liberal berakar pada cita-cita Barat tentang individualisme. Sejarah politik liberalisme berkait erat dengan bangkitnya kelas menengah yang diuntungkan oleh Kapitalisme. Pengaruh liberalisme dalam pendidikan dapat dianalisis dengan melihat komponenkomponennya.

Ketiga, Paradigma Kritis. Pendidikan bagi mereka merupakan arena perjuangan politik. Jika paradigma konservatif bertujuan menjaga status quo dan paradigma liberal bertujuan untuk melakukan perubahan, maka paradigma kritis menghendaki adanya perubahan struktur secara fundamental, terutama dalam politik dan ekonomi masyarakat di mana pendidikan berada. Bagi mereka, kelas dan diskriminasi gender dalam masyarakat tercermin dalam dunia pendidikan. Paham demikian bertentangan dengan pandangān kaum liberal di mana pendidikan dianggap terlepas dari persoalan kelas dan gender yang ada dalam masyarakat.

Jika Descartes memaklumkan pemyataan 'Aku berpikir, maka aku ada', Albert Camus mengisyaratkan, 'Aku pemberontak, maka aku ada'. Pemberontakan metafisis adalah serangan terhadap fitrah sebagai manusia. Karena fitrah itu dilawan, berarti fitrah itu ada. Memberontak terhadap Tuhan juga berarti pembuktian bahwa Tuhan itu ada dalam pemahaman si murtad. Friedrich Nietzsche (1844-1900) adalah pemikir pertama yang berhadapan empat mata dengan 'yang $a b$ surd', dan mencoba mencipta tatanan moral baru minus Tuhan, yang ditarik secara eksklusif dari eksistensi manusia. Camus menyanjung nihilisme Nietzsche dan berkomentar, 'Nietzsche akan menebus

12 Stevan M. Chan, Mendemokratiskan Pembelajaran, Tujuan Pendidikan Liberal (Yogyakarta: Kreasi Wacana, 2002), 19. 
Topik: Globalisasi dan Liberalisasi dalam Bidang Pendidikan

dunia ini'. Dalam kaitan ini, Fowler menyimpulkan,

"Camus adalah seorang humanis liberal. Dalam The Rebelia tawarkan kritik ideologi tuntas dari sudut pandang itu. Camus menjadi 'orang penting' di zaman kita lantaran ia menyusun sistem etis yang sangat mendasar dan persuasif, ditimba dari konteks situasi kemanusiaan sendiri, tanpa mengacu ke prinsip-pninsip a priori. Dalam hal ini ia adalah eksistensialis; disarikannya eksistensi menjadi dalil-dalil yang kemudian akan dipakai sebagai pedoman perwujudan eksistensi itu sendiri. Jelas ia berbeda dengan Jean-Paul Sartre yang berkata bahwa meski manusia menyadari keabsurcan dan kehampaan eksistensi, manusia mesti melekatkan makna dengan cara menigikatkan diri pada tujuan tertentu, melibatkan diri dengan sistem tertentu yang diterimanya sebagai sistem sahih, sambil menunda kesangsiannya. Perbedaan antara Camus dengan Sarte mirip dengan perbedaan antara seseorang yang asyik menceburkan diri dan berenang dengan orang lain yang berdiri dalam air sebatas lutut, menggigil, memeluk bahu sendiri dan giginya gemeletuk kedinginan."13

Tentang liberalisme, A.S. Neill, pendidik dan penulis berkebangsaan Scotlandia ini diakui sebagai figur sentral dalam gerakan 'sekolah bebas' di dunia Barat- mendirikan 'sekolah bebas'-nya pada tahun 1921 di Leiston, sebuah kota kecil di Suffolk, sekitar seratus mil dari London. Sekolah itu dinamai Summerhill, 'Bukit Musim Panas' yang menyiratkan kebebasan dan sinar terang-benderang, warnawarni dan kesibukan. Hingga kini, Summerhillmasih berdiri di bawah pimpinan isteri Neill, Ena.

Tidak seperti Dewey, Neil bukan teoretikus. Dia lebih merupakan sosok
Kepala Sekolah yang berpengalaman. Lantaran tanpa "pangkat ilmiah" inilah gagasan-gagasan Neill mula-mula dicueki orang sebelum ia menerbitkan buku yang sangat kontroversial dan pengaruhnya luar biasa: Summerhill: A Radical Approach in Child Rearing (1960). Buku ini terbit sesudah Summerhill sempat merayakan ulang tahunnya yang ke-40.

Di Summerhill, Neil mencoba menetapkan eksperimen pendidikan tanpa paksaan dan tanpa tekanan terhadap murid. Siswa-siswinya berumur antara 5 hingga 15 tahun. Neil terpengaruh oleh pemikiran pembaharu sebelumnya yakni Homer Lane. la juga menyerap ide-ide Sigmund Freud (melalui tafsiran Wilheim Reich). Neill percaya bahwa anak-anak sesungguhnya cenderung 'baik'. Maka, di Summerhill, derajat guru dan murid sejajar. Wewenangnya pun sama besar. Sekolah ini dijalankan menurut prinsip 'pemerintahan sendiri' yang demokratis di mana sang pendiri juga hanya kebagian satu suara dalam tiap musyawarah. Mau masuk atau tidak, diserahkan kepada anak. Tidak ada ulangan, tes, dan ujian. Tidak ada rapor dan nilai. Anak-anak tidak terlalu disiapkan untuk lulus masuk Perguruan Tinggi".

\section{Otonomi, Desentralisasi, dan Deseremonialisasi}

Isu mengenai otonomi pendidikan berkembang seiring dengan munculnya desakan kuat perlunya demokratisasi dan asumsi kuat di kalangan masyarakat. Tak pelak lagi, ini merupakan imbas dari euphoria reformasi bahwa lembaga pendidikan apa pun merupakan institusi pendidikan yang lebih memahami kelebihan dan kelemahan

13 Ibid. 
dirinya,. Karena itu, mereka harus mampu mengoptimalkan potensi sumber daya yang dimiliki untuk memajukan diri mereka. Lembaga pendidikan apa saja akan lebih mengetahui kebutuhan, khususnya input pendidikan yang akan dikembangkan dan didayagunakan dalam proses pendidikan sesuai kebutuhan dan tingkat perkembangan anak didik.

Berdasarkan asumsi di atas, bila diberi kesempatan secara memadai, setiap lembaga pendidikan sebenarnya memiliki kemauan dan kemampuan mempertanggungjawabkan kinerja dan mutu pendidikannya kepada stakeholders. Dengan demikian, persaingan sehat dengan lembaga lain menjadi mungkin. Untuk itu, masing-masing, secara mandiri, dapat menempuh upaya-upaya kreatif-inovatif dengan dukungan orang tua, masyarakat, pemerintah daerah, dan stakeholders lainnya. Aspirasi masyarakat mengenai otonomi pendidikan secara jelas diakomodasi oleh Undang-Undang tentang Sistem Pendidikan Nasional, khususnya pada Bab XV tentang peranserta masyarakat dalam pendidikan, dan lebih khusus lagi pada pasal 55 mengenai pendidikan berbasis masyarakat. ${ }^{14}$

Isu seputar otonomi pendidikan ini menjadi penting karena pada dasamya otonomi menjadi karakter utama lembaga pendidikan - apa pun namanya - sejak awal mula kemunculannya. Namun, masalah ini sangat mungkin berubah menjadi ancaman jika para penyelenggaranya tidak memiliki kemampuan memadai dalam mengimplementasikan nilai-nilai otonomi tersebut dalam keseluruhan aspek penyelenggaraan pendidikan. Kegagalan pengelolaan pendidikan di Indonesia, menurut penulis, sebenarnya bukan semata-mata karena ada dan tidak adanya otonomi, desentralisasi, dan liberalisasi pendidikan, atau, bukan hanya karena masalah peraturan perundang-undangan dan anggaran, tetapi banyak terkait dengan masalah-masalah di luar pendidikan itu sendiri.

Sebagai contoh penulis dapat mengemukakan bahwa budaya masyarakat Indonesia sesungguhnya masih senang dengan tetesan dari atas, atau dibina oleh pejabat yang lebih tinggi sehingga inisiatifinisiatif strategis dari pengelola pendidikan sangat lemah, dan bahkan praktek pendidikan selama ini masih sangat sentralistik. Selain itu, masyarakat Indonesia masih suka memegang teguh budaya seremonial yang sering mengabaikan substansi atau materi kegiatan secara umum. Upacara-upacara keagamaan di kalangan masyarakat beragama Indonesia seperti peringatan hari besar keagamaan, upacara kultural keagamaan (lebaran, pernikahan, sunatan, kematian, dan lain sebagainya) merupakan bukti seremonialisasi yang berkembang dalam masyarakat.

Dalam konteks pendidikan tinggi, dapat dilihat pada praktek kependidikan di mana banyak acara-acara yang sesungguhnya tidak penting, bahkan sering mengesankan basa-basi dan penindasan serta penghamburan beaya, tetapi justru digemari masyarakat dan dilakukan oleh para pelaku pendidikan. Kalau kegiatan terpenting pada PT adalah Tri Dharma PT, maka yang tidak terlalu mengesankan basa-basi hanyalah kegiatan pendidikan dan pengajaran atau proses belajar mengajar. Sementara itu, bidang yang lain, penelitian-meski banyak pengelola PT yang akan menjadikan PTnya sebagai universitas riset (research university), namun, hingga kini, kegiatan tersebut

14 Undang-undang Republik Indonesia Nomor 20 Tahun 2003 tentang Sistem Pendidikan Nasional (Jakarta: Depdiknas, 2003), 36. 
masih mengesankan basa-basi dan seremonial. Ini dikarenakan lebih dari 50 persen - bahkan mungkin 75 sampai dengan 90 persen produk penelitian PT 'belum' ada artinya. Apalagi kegiatan pengabdian kepada masyarakat yang juga mengesankan basa-basi dan tidak sesuai dengan bidang studi yang ditekuni selama mengikuti pendidikan (kuliah). Kedua kegiatan terakhir ini dilakukan mahasiswa lebih karena ada ketentuannya, bukan karena minat dan fokus yang serius dari mahasiswa. Aspek seremonial biasanya lebih mengemuka daripada substansinya sendiri. Dalam pelaksanaan dan penerapannya pun, para mahasiswa lebih mementingkan proses, bukan produknya yang sangat didambakan masyarakat. Oleh karena itu, langkahlangkah pemberian otonomi dan deseremonialisasiperlu mendapatkan perhatian oleh para pelaku pendidikan dalam semua jenjangnya.

\section{Penutup}

Pada dasarnya, manusia sebagai pelaku pendidikan senantiasa menghendaki perubahan. Di era global sekarang ini, bahkan sejak dahulu, semua yang ada di dunia selalu mengalami perubahan. Yang tidak mengalami perubahan tentu perubahan itu sendiri. Kaum intelektual adalah kelompok masyarakat terdepan yang selalu tidak puas dengan kemapanan dan selalu menghendaki perubahan. Tetapi, perubahan itu tidak mudah diwujudkan semudah atau seperti membalik telapak tangan manusia.

Kaum intelektual bahkan mengalami kebingungan yang dahsyat ketika menghadapi stagnasi kependidikan di negara mereka. Kebingungan demikian selanjutnya memunculkan, paling tidak, tiga paradigma pendidikan: konservatif, kritis, dan liberal. Ketiga paradigma ini disuarakan oleh masing-masing pengikutnya. Mereka menegaskan bahwa paradigma merekalah yang paling tepat untuk meningkatkan kualitas pendidikan di negara masingmasing. Dari sinilah dua kubu pendidikan hadir: yang masih tetap menghendaki stagnasi dan yang menginginkan adanya: dinamisasi.

Paradigma liberal yang banyak mendapatkan perhatian dalam tulisan ini tentu dilakukan melalui proses liberalisasi. Karenanya, liberalisme adalah paradigma dan liberalisasi adalah proses. Jika liberalisasi diartikan sebagai upaya penerapan dan pembudayaan inisiatif-inisiatif strategis dalam bidang pendidikan, maka para pelakunya tentu banyak yang sepakat dengannya. Tetapi, jika liberalisasi hanya dikaitkan dengan perdagangan bebas sehingga komoditi pendidikan yang kulturalistik disamakan dengan komoditi ekonomi, tentu banyak yang tidak sependapat.

Dewasa ini, praktik-praktik yang sentralistik dan seremonialistik dalam dunia pendidikan masih sering diterapkan sehingga pengekangan kreativitas tidak dapat dihindarkan. Sebagai akibatnya, substansi dan kualitas pendidikan di negeri ini masih jauh tertinggal, bahkan jika dibandingkan dengan negara tetangga seperti Malaysia. Agar tidak tertinggal, para pelaku pendidikan sebaiknya menerapkan proses desentralisasi atau otonomi, mengedepankan inovasi dan inisiatif-inisiatif strategis, atau dengan melakukan deseremonialisasi. 
Paradigma Liberal dalam Pendidikan Global; Siswanto Masruri

\section{Daftar Pustaka}

Sabri, Abdul Fattah dan 'Ali 'Umar. 1953."Kisra wa al-Fallah al-Shaikh" dalam Al-Qira'ah al-Rashidah, al-Juz al-Thalith, Mesir: Dar al-Ma'arif,

Sami, Ali al-Nashar, 1947. Manahij al-Bahts 'Inda Mufakkir al-Islam wa Naqd alMuslimin li al-Manthiq al-Aristhatalisi, Iskandariyah: Dar al-Fikr al-'Arabi.

Hadikusuma,Djarnawi , 1979. Derita Seorang Pemimpin, Yogyakarta: Persatuan.

Francis Wahono,. 2001. Kapitalisme Pendidikan, Antara Kompetisi dan Keadilan, Yogyakarta: Insist Press, Cindelaras Bekerjasama dengan Pustaka Pelajar.

Franz Magnis-Suseno. 2001. Pemikiran Kart Marx, Dari Sosialisme Utopis ke Perselisihan Revisionisme, Jakarta: PT Gramedia Pustaka Utama.

J.W. Drapper. 1966. History of the Conflict Between Religion and Science, London:

Kathleen Newland dan Kemala Chandrakirana Soedjatmoko (Penyunting), 1994. Menjelajah Cakrawala, Kumpulan Karya Visioner Soedjatmoko, Jakarta: PT Gramedia Pustaka Utama Bekerjasama dengan Yayasan Soedjatmoko.

Mark Olssen, John Codd and Anne-Marie O'Neill. 2004. Education Policy: Globalization, Citizenship and Democracy, London: Sage Publications.
Muhammad lqbal. 1966. Pembangünan Kembali Alam Pikiran Islam, Osman Raliby (Penerjemah). Jakarta: Bulan Bintang, 1966.

Paulo Freire, Ivan Illich, Erich Fromm dkk., 2001. Menggugat Pendidikan, Yogyakarta: Pustaka Pelajar.

Paulo Freire. 1985. The Politics of Education: Culture, Power, and Liberation, Massachussets: Bergin and Garvery Publishers.

Robert Brifault. 1919. The Making. of Humanity, London: 1919.

Robin Barrow. 1978. Radical Education: $A$ . Critique of Freeschooling and Deschooling, London: Martin Robinson.

S.I. Poèradisastra, 1986. Sumbangan Islam kepada IImu dan Peradaban Modern, Jakarta: P3M.

SKH Jawa Pos, Kamis, 5 Mei 2005, 7.

Soedjatmoko, 1991. Soedjatmoko dan Keprihatinan Masa Depan, Yogyakarta: PT. Tiara Wacana.

Stephen R. Covey. 2005. The 8th Habit, Melampaui Efektivitas, Menggapai Keagungan, Jakarta: Gramedia Pustaka Utama.

Stevan M. Chan. 2002. Mendemokratiskan Pembelajaran, Tujuan Pendidikan Liberal, Yogyakarta: Kreasi Wacana.

Tempo, Edisi 19-25 Desember 2005.

Thomas G. Weiss dan Cindy Collins, 1996. Humanitarian Challenges and Hu- 
Topik: Globalisasi dan Liberalisasi dalam Bidang Pendidikan

manitarian Intervention, Colorado: Westview Press.

Undang-undang Republik Indonesia Nomor 20 Tahun 2003 tentang Sistem Pendidikan Nasional, Jakarta: Depdiknas, 2003.
William F. O'Neill, 2001. Educational Ideologies: Contemporary Expression of Educational Philosophies, diterjemahkan ke daiam bahasa Indonesia dengan judul, Ideologi-ideologi Pendidikan, Yogyakarta: Pustaka Pelajar, 2001. 